\title{
An Analysis of the Health Hazards Posed by a Surge of Unaccompanied Alien Children to the Lower Rio Grande Valley Border
}

\author{
Tyann Blessington*, Andrew Hickey, Diana Y. Wong, Mark Freese and Teresa Quitugua \\ National Biosurveillance Integration Center, District of Columbia, DC, USA
}

\section{Objective}

To categorize and assess the health impacts of the 2014 surge of unaccompanied alien children to the Lower Rio Grande Valley Border.

\section{Introduction}

Unaccompanied alien children (UAC) are undocumented migrant children who come to the United States unaccompanied by a parent or guardian. The number apprehended UACs originating from the Central America counties of El Salvador, Guatemala, and Honduras have increased since FY 2012. Since the beginning of fiscal year 2014, more than 57,000 UACs have been apprehended; double the number that was apprehended in FY 2013. The majority of UACs were apprehended and processed in the Customs and Border Protection's (CBP) Rio Grande Valley (RGV) Sector of South Texas. The CBP facilities were not designed to house or care for children for extended periods. Resources and personnel were significantly strained in the management and care of UACs.

\section{Methods}

In collaboration with multiple partners, the National Biosurveillance Integration Center (NBIC) provided an integrated analysis of the health issues that UACs experienced before leaving their home country, while in transit to the U.S., and while being housed in U.S. custody. Analytical reports on the health security of Mexican and Central American nations were shared with federal partners. CBP Office of Intelligence and Investigative Liaison (OIIL), Office of Health Affairs (OHA) Workforce Health, and NBIC analysts evaluated apprehension rates, migration patterns, and potential health hazards related to immigration to our southwest border. NBIC began reporting on border health issues at the beginning of FY 2014, through briefs to DHS components and OHA leadership and through timely situational reports to federal, state, and local partners. The NBIC assisted federal preparedness by reporting the occurrence of infectious disease, the major infectious and non-infectious diseases, recent notable epidemics, and other major health issues affecting Mexican and Central American nations. The NBIC assisted in the healthcare response by evaluating health data of apprehended UACs, evaluating current practices through OHA and NBIC personnel deployments, and by providing situational and epidemiological awareness of the most probable infectious agents afflicting UACs in CBP custody facilities.

\section{Results}

Many impoverished Central Americans lack the ability to receive adequate healthcare and organized criminal elements have hindered access to available resources. Even though the health security of these nations have been strained, the infectious diseases afflicting Central American children largely mirror those are reported in the U.S. The majority of illnesses afflicting UACs are relatively minor and do not pose a risk to the local populations. Common health ailments, including lice, scabies, influenza, and chicken pox are treatable and are acute infections of limited duration.

\section{Conclusions}

Timely identification and early awareness of health hazards is essential for protecting personnel, ensuring appropriate resource allocation, and supporting public health intervention strategies. For many UACs, the travel from their home country to the U.S. border was physically demanding and required optimum health. The health impacts of UACs to local U.S. populations were minimal.

\section{Keywords}

Unaccompanied Alien Children; Border; DHS; Health; Risk Assessment

*Tyann Blessington

E-mail: tyann.blessington@hq.dhs.gov 